\title{
Global Demographic Pressures and Management of Natural Resources - Foresights about the Future of Mankind
}

\section{Angelica BĂCESCU-CĂRBUNARU ${ }^{1}$}

Abstract
The article presents the current demographic pressures that affect
forecasting depending on environmental sustainability, increasing resource demand,
resources management, the uneven distribution of waters, climate changes, the natural
environment - pollution, the use of nuclear energy, etc.
The article takes into account foreseeing the future of mankind meaning care for future
generations, with reference to the ways in which the management of national natural
resources is realized. The sustainable use of natural resources raises a series of
challenges at a global level and this responsibility is reflected in several international
environment protection agreements.
In conclusion, the future of humankind is a process threatened by natural,
economic, social, technological, epidemiological risks, and the developed countries
can no longer maintain their advantages if not pushing forward for developing
countries, including through environmental and natural resource policies.

Keywords: forecasting the future of humankind, natural resources management, demographic pressure, food pressure, ecological footprint, sustainability

JEL classification: C53, J11, Q01, Q25, Q56, R58

DOI: $10.24818 /$ RMCI.2018.1.40

\section{Introduction}

Is increasingly evident that humankind has developed so far without a particular strategy, i.e. our civilization left itself ridden by the tempting, though sometimes misleading wave of the scientific and technical progress. "No generation from anywhere in the world, cannot hope to grow by the same political, economic, social and psychological patterns as the previous generations. In a world of a constant motion and change, nothing is more stable than the change: it is an objective process that cannot be ignored" (Năstase M., Giuclea M., Bold O.).

Under the circumstances of the strong competition across nations, the human society accumulated certain bombs in human development challenges, such as nuclear bombs, environmental pollution, poverty, etc. which, if not being subject to disposal on time, could head the world towards disaster, a disaster which can jeopardize the very existence of life on earth.

1 Angelica Băcescu-Cărbunaru; The Bucharest University of Economic Studies ; email: mihaela.carbunaru@csie.ase.ro; +4021.319.19.00/383

$40 \quad$ Review of International Comparative Management Volume 19, Issue 1, March 2018 
Therefore, in the current period people will have to inquire where exactly is the human society moving, what will be the human society tomorrow, which are the sprouts of that change and which are the strategies to support the society in moving on right direction.

When the population is continuously growing and increasingly scarce natural resources, there is a need for a new conception in the management of the planet, first of all lucidly perceiving where the humankind is going. This requires the most realistic forecasts for the future of humankind, identifying some possible scenarios on a given timeframe that characterize at least the first quarter of the twenty-first century. Of course, this requires firstly a sober perception of the world we live in, with a scientific knowledge on the forces of good propelling the general progress and evil forces hampering the development and whose proliferation needs to be cut out.

\section{Demographic pressures that influence the future of humanity}

"Humankind is being buffeted by the forces of demographic change" (Bloom 2016).

If we speak of population growth, many of us immediately imagine scenarios on how will we succeed in procuring living resources.

"In order to ensure our needs, we now need the equivalent of 1.7 planets" say two non-governmental organizations, Global Footprint and WWF — World Wide Fund for Nature. "The cost of hyper-consumption is already visible: water shortages, desertification, soil erosion, declining productivity of agriculture and fisheries resources, the disappearance of species of animals and deforestation", show the same sources. If relating the Earth's surface and the number of inhabitants, it results the land area that is needed in order to provide the necessary resources and to neutralize the waste generated by our consumption. Thus, the ecological footprint is calculated, an index measuring the pressure exerted by humankind upon the ecosystems.

Thomas Robert Malthus (2005) feared that agricultural land would be incapable of providing enough food for an ever-growing population (George, Schillebeeckx, and Liak). The forecasts of a world exhausted by the humankind occur even in popular culture. In some areas of the globe, the population increase represents a peak of concerns due to increasing pressures on land, the labor market and obviously on government budgets. Multiple demographic phenomena, such as ageing, migration, urbanization and increased average life duration, make even more complex the overpopulation process."

The world continues to experience the most significant demographic transformation in human history. Changes in longevity and fertility, together with urbanization and migration, are powerful shapers of our demographic future, and they presage significant political, social, economic, and environmental consequences." (Bloom 2016). Some Member States are facing significant migration of labour force, such as our country. Others are in a position to carry out 
a "demographic dividend" based on an expected growth of working-age adults such as China (F. Wang, I. Mason A. Mason). These crossed dynamics define today the demographic changes. In the paper "The Population Bomb" published in 1968, Paul Ehrlich warned upon the global disaster can occur due to overpopulation.

"In July 2014 the UN for the first time issued official probabilistic population projections for all countries to 2100. These projections quantify uncertainty associated with future fertility and mortality trends worldwide" (Alkema, Gerland, Raftery, Wilmoth, 2015).

The forecasts made by the UN on the demographic perspectives of the world population were the subject of a regular review carried out since 1951 by the Population Division of the Department of Economic and Social Affairs of the United Nations Secretariat. "According to the results of the 2017 Revision, the world's population numbered nearly 7.6 billion as of mid-2017 (table 1), implying that the world has added approximately one billion inhabitants over the last twelve years. Sixty per cent of the world's people live in Asia ( 4.5 billion), 17 per cent in Africa (1.3 billion), 10 per cent in Europe ( 742 million), 9 per cent in Latin America and the Caribbean (646 million), and the remaining 6 per cent in Northern America (361 million) and Oceania (41 million). China (1.4 billion) and India (1.3 billion) remain the two most populous countries of the world, comprising 19 and 18 per cent of the global total, respectively".

Table 1: Population of the world and regions 2017, 2030, 2050 and 2100, according to the medium-variant projection based on U.N. data

\begin{tabular}{|l|r|r|r|r|}
\hline \multirow{2}{*}{ Region } & \multicolumn{4}{|c|}{ Population (millions) } \\
\cline { 2 - 5 } & 2017 & \multicolumn{1}{|c|}{2030} & \multicolumn{1}{c|}{2050} & \multicolumn{1}{c|}{2100} \\
\hline World & 7550 & 8551 & 9772 & 11184 \\
\hline Africa & 1256 & 1704 & 2528 & 4468 \\
\hline Asia & 4504 & 4947 & 5257 & 4780 \\
\hline Europe & 742 & 739 & 716 & 653 \\
\hline Latin America and the Caribbean & 646 & 718 & 780 & 712 \\
\hline Northern America & 361 & 395 & 435 & 499 \\
\hline Oceania & 41 & 48 & 57 & 72 \\
\hline
\end{tabular}

Source: United Nations, Department of Economic and Social Affairs, Population Division (2017). World Population Prospects: The 2017 Revision. New York: United Nations.

On 1 July 1990, the usual resident population in Romania was 23,206,720 inhabitants and on 1 July 2015 was 19,819,777 inhabitants. This population will exert increasing pressure on the physical space, food, living space, renewable and non-renewable natural resources, the environment and labor market.

If in 1990 the global population density per square $\mathrm{km}$ was approximately 40 inhabitants, this could rise to 59 inhabitants per $\mathrm{km}^{2}$ in 2025 and the population growth will continue to put pressure on the environment and emptying villages

$42 \quad$ Review of International Comparative Management Volume 19, Issue 1, March 2018 
through migratory exoduses towards city pattern (Food and Agriculture Organization). Naturally, it would contribute to improving the living conditions of the population and the civilization in general, but it also has multiple implications for the human condition generated by the population concentration in large agglomerations.

It should be noted that in recent decades the degree of cities concentration has increased, so that in 1950 there were 90 cities with more than 1 million inhabitants and 512 cities in 2016. The forecast for 2030 is of 662 cities (United Nations Department of Economic and Social Affairs, Population Division - 2016). This requires a reconsideration of the city in terms of size and structure, in order to fight against a giant, monstrous and overcrowded city, with poor living conditions and characterized by the humiliation of human personality.

The forcible mass uprooting of small-scale farmers and the rural population in general, brutally removed from their environment, caused serious economic and social imbalances, thus widening the gap between towns and villages, thus becoming natural a rural world far lagging behind and the population belonging to urban environment. This puts strong pressures on the environment, soil and waters, agricultural and forestry resources, coastal marine areas and continental shelves, as well as on the diversity and on the global ocean.

Throughout the history, the humankind put pressure on natural agricultural resources, as the main source of food that in return has influenced the typologies for human consumption. This food pressure has led to increased agricultural production, which in turn entailed the multiplication of population over wide areas of the planet. If we take into account the axiom that within the system of human needs food has absolute priority, it is clearly emerging the need for food production to be at the top of the agenda. Of course, the demographic pressure upon the food area, expressed in the norm of land needed to feed a person decreased continuously. Thus, if during the civilization of hunting the norm of land was 5,000 hectares per person, in the civilization of plough was 2 ha, and today, in the period of peak agriculture, the norm of land reached 0.08 ha.

It is recognized that we owe the life on earth mostly to green plants, $2 / 3$ being forests. Occupying more than $30 \%$ of the world's surface, forests provide at the same time more than half of the oxygen produced worldwide by photosynthesis. Thus, the forests ensure the dynamic balance through the annual absorption of around 15-20 million tones carbon dioxide and, at the same time, the production of some 10-15 billion tones of oxygen.

The human development model depends largely on waters that, the same with the food, has become a global problem. The relative scarcity of potable water, in combination with the dramatic effect of local shortages on agriculture and livelihood, has put water risks and opportunities among the top sustainability issues (Ernst \& Young, 2012; McNally, 2015; PwC, 2011). According to the United Nations - 2012, 783 million people do not have proper access to drinking water, and, in sub-Saharan Africa, water is unavailable to over $40 \%$ of the population. More than 850 million people are undernourished and at risk of starvation, and 
over 1.1 billion do not have access to energy, which necessitates innovative business models for off-grid rural areas (Schillebeeckx, Parikh, Bansal, \& George, 2012).

Forecasting the future depends on the category of existing waters, as follows.

Natural waters, although representing the most convenient source are unevenly distributed across areas and territories, are restricted to a certain period of use, requires considerable expense for the calibration of their release, their quality has deteriorated due to pollution and on large parts of the planet account for flood hazards.

The arranged waters have developed strong economic (high costs) and environmental restrictions, hazards of flooding and earthquakes and limits of use could increase up to 40-50 years.

Groundwater under the form of underground lakes and rivers, have the advantage that are less polluting but they are situated in the arid areas where there is the greatest need of water and their use involves high pumping costs.

The waters of the polar ice caps comprise over $77 \%$ of the world's freshwater resources, which could cover the requirements of humankind on several thousand years. The disadvantage is that they are almost entirely in the polar areas and have particular implications on the environment, climate, and rainfall patterns worldwide due to displacement, with only limited possibilities for use in adjacent areas.

Marine water resources are the safest reserves that can meet the requirements of freshwater perspective of humankind, but has the disadvantages of the high costs of desalination and seas and oceans waters pollution. This requires new desalination technology under economic efficiency conditions. No economic growth model can be developed without taking into account the environment, whose pollution has great implications on diversity, fauna and flora, the climate of the planet, global warming which by the "greenhouse effect" can give 2-4 degrees in addition to the Earth's temperature (Brown, Bellamy, 2007). Under such circumstances, the environment is acting as a general fixed capital subject to moral and physical wear out and should be recovered from the national product. Therefore, measures should be taken at national and international levels, such as reducing the pollutant nature of some industrial sub-sectors, stopping deforestation, promoting organic farming, introducing taxes and fees on the use of natural marine resources and on related pollution, etc.

The danger of using nuclear energy is the catastrophic degree of pollution as well as the risk to extend its geographical scope and to be out of control. Therefore, the realistic solution does not seem to be the non-proliferation and nuclear test ban, but rather the destruction of all nuclear arsenals and completely banning nuclear weapons or other similar weapons of mass destruction, which could endanger the survival of the planet (Stiglitz, 2005).

44 Review of International Comparative Management Volume 19, Issue 1, March 2018 


\section{Management of natural resources (NRM)}

Barsch \& Bürger (1996) have shown that natural resources are materials created in nature that are used and usable by humans. They include natural substances (e.g., soil, water, timber, animals, land) and energy supplies (e.g., coal, gas) that serve to satisfy human needs and wants (Minc 1976). Natural resource management is the responsible supervision or handling of these resources (learn.org).

American economist professor E. Zimmermann defines this process: „Resources are not, they become“ (Zimmermann 1951, citied in Barsch and Bürger 1996). His "functional theory" sustained that "materials are not resources until humans take advantage of them". This idea supports the late Julian Simon's argument that humans are the ultimate resource. Zimmermann rejected the assumption of fixity. Resources are not known, fixed things; they are what humans employ to service wants at a given time (Bradley R.). To Zimmermann only human "appraisal" turns the "neutral stuff" of the earth into resources. What are resources today may not be tomorrow, and vice versa. "Resources are highly dynamic functional concepts; they are not, they become, they evolve out of the triune interaction of nature, man, and culture, in which nature sets outer limits, but man and culture are largely responsible for the portion of physical totality that is made available for human use" (Zimmermann 1951, 814-15). Zimmermann concluded that "knowledge is truly the mother of all resources" Since this concept of natural resources was criticized as too anthropocentric, today many interpret resources much more broadly than in this functional or utilitarian sense. "In that context, resources are the abiotic, biotic and cultural attributes on, in or above the Earth" (Mitchell 2002, 6). We use these varied natural resources in different ways to satisfy our needs and wants - eating and drinking, growing food, making clothes, building houses and transport, for example. However, natural resources are not infinitely available for human use. Not only non-renewable but also (theoretically) renewable resources are limited. Enders \& Querner (1993) have shown that communities should be economical with their natural resources in a sustainable manner. In many regions of the world, this general shortage problem is aggravated by the degradation and destruction of natural resources (e.g., soil erosion). This is mainly due to overuse or a non-adapted use of these resources (Förch and Schütt 2004 a). The resistance and regenerative power of many landscape systems are thereby exceeded. Water balance problems threaten the living conditions of communities and limit the use of resources (e.g., destructive flooding, droughts). These problems are indicators of a non-sustainable management of natural resources. As a result, some possible uses of resources are increasingly restricted. Food production and rural livelihood may be threatened as well as resource use conflicts may occur (Beck et al. 2004). In recent years, the economic growth doubled the ecologic impact upon the planet, while the pressure upon the environment grew fast, which led to the emergence of a deficit of natural resources both for the present and the next generations Sima E. (2010, pp.67). According 
Department of Earth Sciences - Freie Universitat Berlin, a sustainable management of natural resources is needed to avoid further degradation and destruction, to solve the water balance problems and to improve the conditions of the resources. This requires careful and competent planning. For this, skilled planners and managers are required (Förch and Schütt 2004 a). In the past few decades, management of natural resources has become an important topic in practically all societies. It emerged from the increasing realization that an isolated resource management, which used to be prevalent, has not been successful (Department of Earth Sciences - Freie Universitat Berlin). Ewert (2004) and Heathcote (1998) have both shown that "this can be attributed to the non-consideration of the interactions of the individual resources, the linkages between these resources and other physical and human components of the ecosystem and thus of the impacts of management actions imposed on one resource on the other components and processes within the ecosystem". In integrated resource management, by contrast, the ecosystem is managed as one entity. All components of and processes within the ecosystem are considered, as well as the interactions between them. This includes humans and their activities as well as the effects of their resource use on the system (Department of Earth Sciences - Freie Universitat Berlin). An integrated resource management and planning refers to modern ecosystem management, emphasizing the management of systems rather than of individual components of the system (Förch and Schütt 2004 b; Heathcote 1998). Ratter (2002) and Heathcote (1998) have both shown that "the following elements have thus to be integrated: the different components of the ecosystem including the population with their different interests, values and perspectives as well as their activities; the different disciplines dealing with the individual spheres; the various governmental departments, institutions and organizations that are responsible for the individual domains; the various tasks and activities. In view of the human dependence on natural resources and their exhaustibility a natural resource management and a societal development are required which are sustainable and environmentally appropriate (Förch and Schütt 2004 b). Resources have to be managed in such a way that the demand of the present generation can be satisfied without exhausting, degrading or destroying them in the long term in order to preserve them as a basis of survival for future generations (intergenerational equity) (Lal 1995). Such a management for the benefit of the people and in harmony with the environment implies that resources are only to be used if they are renewable (Förch and Schütt 2004 b) and are used at rates that correspond to the replenishment rates or at an intensity which does not exceed the carrying capacity of the system. Unfortunately, most management practices of today are not sustainable (Ewert et al. 2004). To achieve a sustainable development at least two requirements should be considered (Department of Earth Sciences - Freie Universitat Berlin): to address also intergenerational equity issues - people who don't have enough food today will be less concerned about the needs of future generations (Mitchell 2002) and to develop environmental knowledge and skills to allow for an economically sustainable utilization of resources. Why do we need to use our resources carefully? The answer is given in figure 1. For instance, a

46 Review of International Comparative Management

Volume 19, Issue 1, March 2018 
ban on the use of forests should not be imposed: instead, a sustainable forest management concept should be elaborated in cooperation with the population. A multitude of forest products (such as herbs and honey) can be used sustainably by the population for the satisfaction of their needs and for income generation (Förch and Schütt 2004 b). The UN proclaimed "Education for a sustainable development" as a UN decade from 2005-2015.

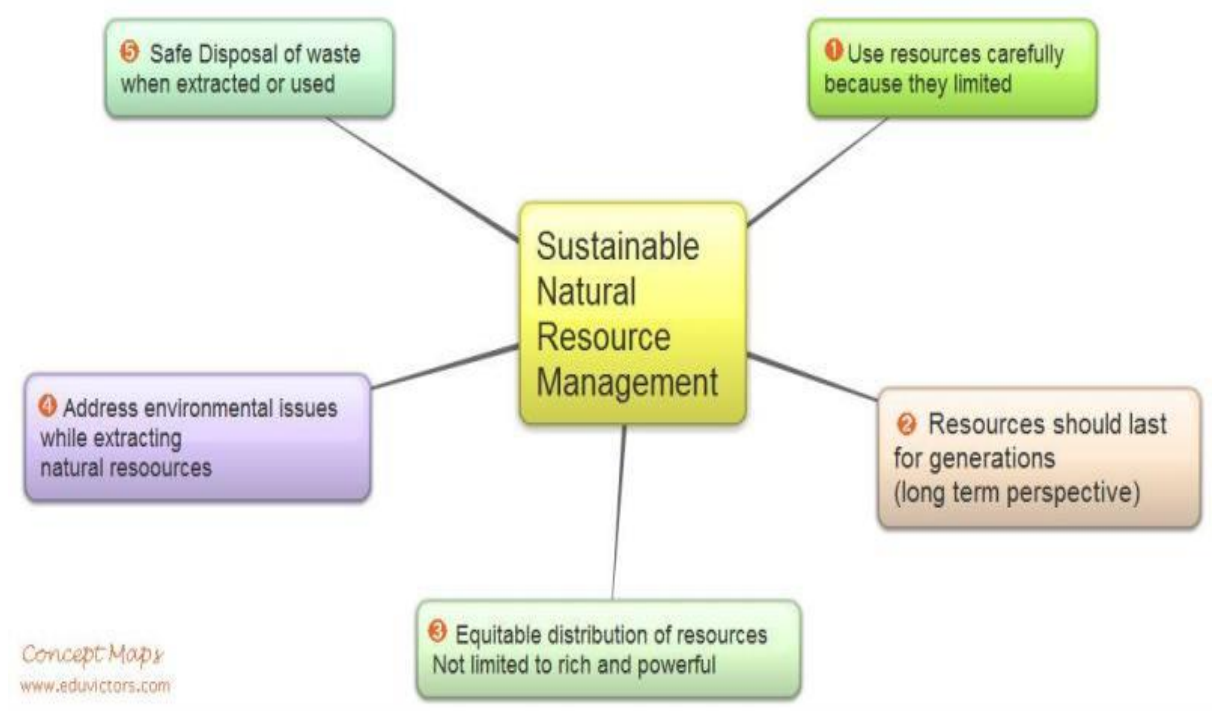

Figure 1: How to manage your natural resources sustainably

In accordance with national territorial characteristics, natural resource management is applied at local, regional and state level. We will see some similarities and differences between the accomplishment of this very complex process at the level of a large federal state as a continent, Australia, the countries of southern Africa where the majority of people live with and depend on natural resources and our country.

Jennifer Bellamy have shown in "Federalism and Regionalism in Australia: New Approaches, New Institutions?" the above considerations regarding „Adaptive Governance: The Challenge for Regional Natural Resource Management".

"In Australia, the current system and pattern of use and management of our natural resources has developed over a long period during times when people commonly considered these resources as largely unlimited in terms of capacity for productive use and when beliefs in people's rights to use their land as they wished were particularly dominant (e.g. Cocks 1992). Institutional arrangements for managing our natural resources traditionally involve numerous individual, singlefunction federal and state agencies, each pursuing its own legal mandate through developing and implementing policy dominantly focused on single issues (such as 
sustainable production, water supply or nature conservation). Over some period of time, this system developed numerous natural resource policies and government incentives (e.g. encouraging land clearing for development) which often proved to have conflicting or unintended and environmentally-undesirable effects (e.g. ANAO 1997; The Senate Committee Inquiry 2004). With growing recognition that the impacts of past resource use policy and practices are becoming socially, economically and environmentally unacceptable, the term 'natural resource management' (NRM) emerged in the mid to late 1990s in Australian national and state policy arenas as an integrative and systemic concept to address the complex sustainability issues of our interconnected social and natural systems. In 1999, a federal policy discussion paper on Managing Natural Resources in Rural Australia for a Sustainable Future on developing a national policy for natural resource management defined NRM as 'protecting, maintaining and enhancing natural resources in rural Australia to provide the basis for sustainable production, healthy ecosystems (including healthy rivers and estuaries) and viable rural communities' (AFFA 1999, p.1). It also clearly argues that 'policy approaches for NRM need to be applied in an integrated way across regions and catchments and at the local or farm levels' (AFFA 1999, p.1). The current management of Australia's natural resources is multi-jurisdictional involving cooperative arrangements of the three spheres of government - national, state/territory and local (e.g. Bates 2003; Walter Turnbull 2006). Under the Australian Constitution, responsibility for the legislative and administrative framework within which natural resources are managed lies with the State and Territory governments, who in turn have traditionally devolved some responsibilities particularly relating to land use and development planning to local governments. The Australian Government's involvement in NRM focuses dominantly on matters of national environmental significance and fulfilling Australia's international obligations. The laws that are made for NRM matters by the federal government draw their validity from other heads of power in the Constitution, such as taxation power, trade and commerce or external affairs power (HRSCEH 2000). NRM governance within Australia's federal system, therefore, involves a complex system of multiple 'nested' or polycentric decision-making arrangements (versus neatly hierarchical) being carried out concurrently across a range of political decision-making levels (e.g. national, state, region, local) and horizontally across a fragmented array of territorial and sectored areas. It is presented diagrammatically in figure 2 . This system is continually evolving at all political and sectored levels. For example, each state or region is evolving in different ways, for different reasons, in varying contexts and at different rates. At each level of this complex multi-layered and polycentric system, there are different emergent properties and problems to be addressed (Knight, Bates, 2013). Moreover, the different levels may be coupled by a diverse range of relationships that involve an iterative process of devolution and feedback of functions and outcomes within and between different decision-making levels (e.g. federal to local and vice versa). 


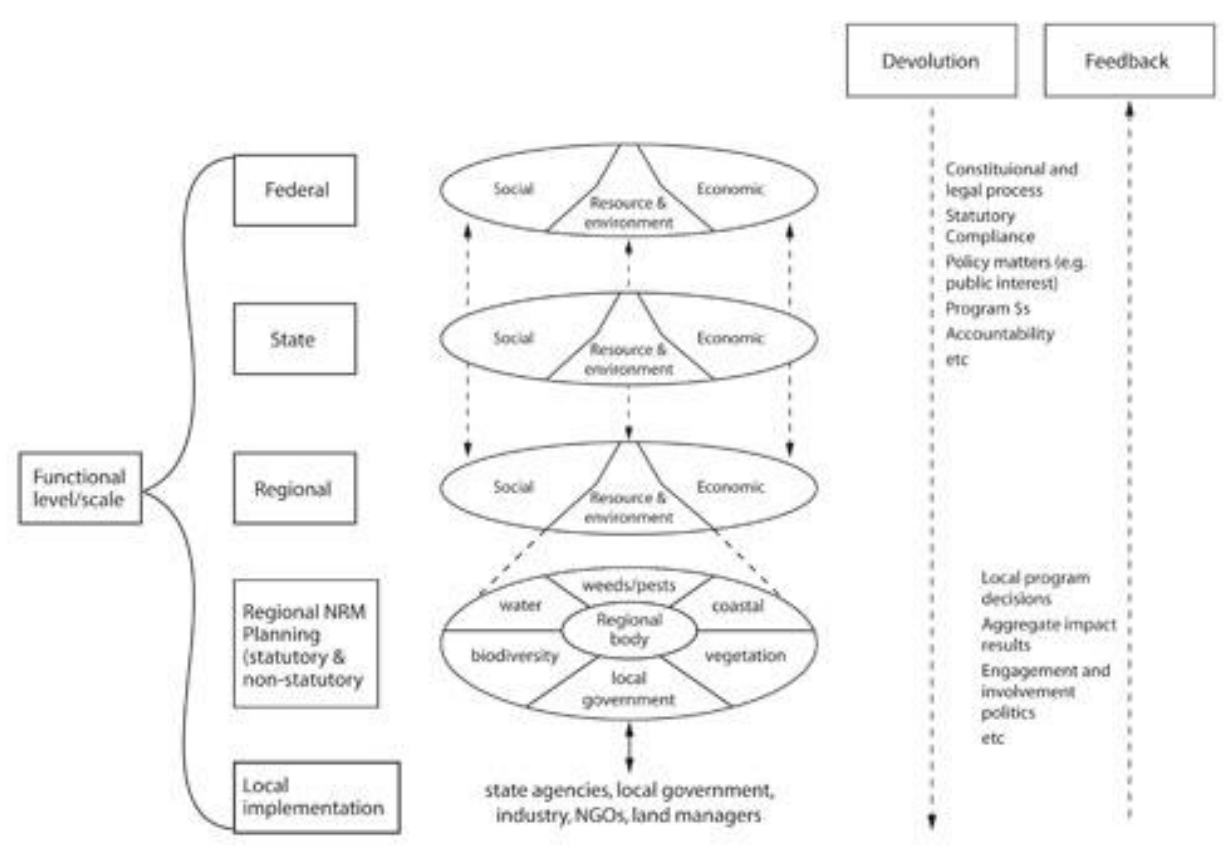

Figure 2: The Australian Natural Resources Management Model

Source: Figure 7.2. NRM governance - a complex multi-layered and polycentric system (Bellamy and McDonald - 2005)

Through the new regional delivery arrangements, 56 NRM regions are defined across Australia by spatial boundaries relating largely to natural biophysical characteristics (e.g. catchments and bioregions) and their intersection with state and territory boundaries. The primary purposes of the regional bodies are to guide NRM planning strategy and investment priorities within their respective regions, and to provide the mechanism for greater community-based NRM." A lot of similarities also characterize the NRM in Canada, another big country as a continent and undeniably among the world's most environmentally and natural resources progressive producers.

According the "Community- based natural resource management manual" published in 2006 by the WWF-World Wide Fund for Nature (formerly World Wildlife Fund) Southern African Regional Office (SARPO), we will mention the guidelines important for natural resources management in Southern Africa.

"All the countries in Southern Africa are currently facing many challenges. These include: low rates of economic growth; severe reduction of natural resources 
in areas of high population density; increased frequency of extreme weather events (both droughts and floods); and HIV/AIDS.

It's necessary an community-based natural resource management (CBNRM) in Southern Africa. CBNRM is based on the principle that land and natural resources should be managed by those people who live with and depend on them. CBNRM does not involve wildlife only but other natural resources and community development as well (World Wide Fund for Nature - SARPO).

Over time, a set of principles has emerged from the analysis of the performance of CBNRM programmes in Botswana, Namibia, Zambia and Zimbabwe. Briefly, these are:

- To determine whether the benefits of managing a resource exceed the costs, the resource must have a measurable value to the community.

- Those communities living with the resource should receive higher benefits than those who do not.

- Smaller groups are more likely to better manage their resources than larger groups.

- The community or group that lives with the resource should also be the same as the group that makes the decisions over the resource and the same as the group that benefits.

A model for achieving resource management for these countries is represented in the diagram below (figure 3).

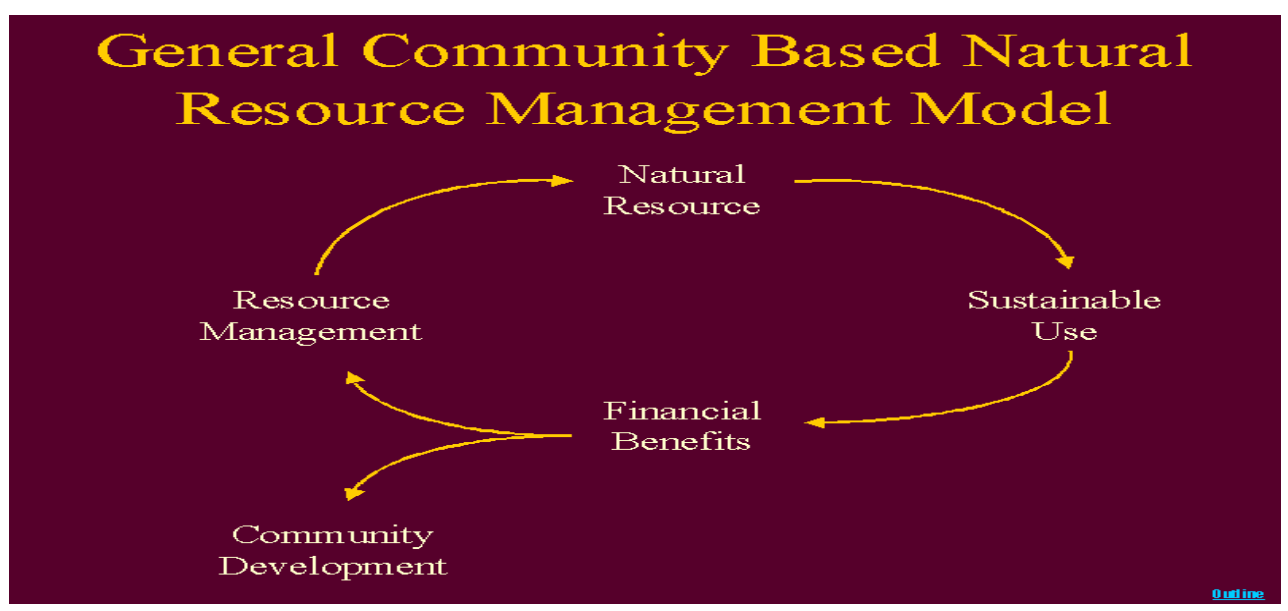

Figure 3: NRM model for countries in southern Africa

Sima (2010, pp. 67-86) states that "Due to the bio-geographical conditions, Romania has a diversified and balanced environment, in which vast rural areas are integrated, which generally stand out by a good preservation of the natural soil and water resources, by the variety of the traditional landscapes and a remarkable biological diversity". In our country the restoration, conservation and consolidation of ecosystems as well as the efficient use of resources are defining objectives of the 
National Rural Development Program starting with SAPARD 2000-2006 (Special Accession Programme for Agriculture and Rural Development) and continuing with National Rural Development Programme 2007-2013 respectively National Rural Development Programme 2014-2020. European funding for achieving these primary goals has been materialized through the emergence of associations such as the Water Users Association (AUA) as key actors. The World Bank simultaneously supported several projects aimed at developing strategies for the rehabilitation and modernization of irrigation and drainage systems and so on (Berca, 2003).

Until July 2013, the Rural Development Directorate, the managing authority for the NRDP, the National Rural Development Program, had selected 82 GALs nationwide. In December 2017 there was a number of 234. Such structures are funded through a budget through the European Agricultural Fund for Rural Development, with the aim of participating in the co-financing of Leader-type projects in the coverage area. GALs develop an integrated local development strategy for rural development (acronym SDR) and are responsible for its implementation (Bulgaru, 1996). Thus, the basic entities formed in the form of a partnership established in a rural area bringing together representatives of the public, private and civil society sectors in that territory, created in order to implement the LEADER (Liaison Entre Actions de Développement de l'Economie Rural Development), aim to implement measures that require a responsible use of resources. "In general, the natural resources of the Romanian rural area are well preserved. The agricultural land with high natural value cover an important area, but both the abandonment of agricultural resources and the inadequate farming practices appeared as a result of the lack of specialty knowledge or of the limited financial resources, which influenced biodiversity in a negative way and determined the emergence or the aggravation of soil erosion phenomena (Sima, 2010. pp. 70). In this context, both agriculture and the forestry resources in Romania can play an important role in the fight against the climate changes, which have been manifest in recent years mainly by floods and high temperatures and prolonged drought" (Sima, 2010, pp.86).

\section{Conclusions}

From all the above we can deduce that forecasting the future of humankind is a challenging process with risks and pitfalls, i.e. natural risks, such as flooding, cyclones, climate changes, earthquakes, etc. as well as economic risks, such as the economic crisis, unemployment, inflation, monetary crisis etc. We must not neglect social risks, such as extreme poverty, lack of housing, hunger, social tension and technological risks of ambivalent nature such as those related to progress and nonprogress of chemistry, biology, nuclear energy, computing and cybernetics, etc.

There should also be taken into account the epidemiological risks, such as the emergence of infectious diseases that may endanger human beings or the risks of military conflicts between countries and major terrorist movements. The World 
Economic Forum (2008) reported that supply chain disruptions, food security, energy security, and systemic financial risks are the four most important emerging issues. The first three are intrinsically connected to natural resources, and they impose grand managerial challenges. Policymakers are expressing growing concerns about the influence of resource availability on their country's growth and local companies' ability to compete in global markets. Ernst \& Young's (2013: 21) report on growing trends in sustainability pointed to the "increased risk and proximity of natural resource shortages," meaning that assessing the availability and reliability of strategic business materials and developing risk management plans to address supply disruption contingencies become strategic imperatives. George, Schillebeeckx, \& Liak (2015) have shown in "The management of natural resources: an overview and research agenda" that "these recent evolutions in the natural resource debate and the presence of scarcity-related issues across a wide variety of renewable and non-renewable resources, local and global challenges, small, medium, and large enterprises, and resource-rich and resource-constrained countries evidence a clear need for management scholars to engage and support this debate with systematic evidence".

In conclusion, since Earth is only one, developed countries need to understand that it is no longer possible to further develop nor can maintain the benefits they have if the countries lagging behind from economic and social standpoint are not taking off towards progress.

\section{References}

1. Alkema, L., Gerland, P., Raftery, A., \& Wilwoth, J., 2015, The United Nations Probabilistic Population Projections: An Introduction to Demographic. Forecasting with Uncertainty, Foresight, issue 37, International Institute of Forecasters, pp. 19-24.

2. Băcescu, M., Băcescu-Cărbunaru, A., 1997, Macroeconomics and Macroeconomic Policy, All Publishing House, Bucharest.

3. Berca, M., 2003, Engineering and resource management for rural development, Ceres Publishing House, Bucharest.

4. Bloom, D., E., 2016, Demographic Upheaval, Finance \& Development, International Monetary Fund, Vol. 53, No. 1.

5. Bradley, L., R., 2004, Are we running out of oil? "Functional theory" says no, PERC Reports, https://www.perc.org/sites/default/files/sept04.pdf

6. Brown, A., J., Bellamy, J., A., 2007, Federalism and Regionalism in Australia: New Approaches, New Institutions? ANU Press, Chapter 7: Adaptive Governance: The Challenge for Regional Natural Resource Management, pp. 95-118, https://www.jstor.org/stable/pdf/j.ctt24hdnw.11.pdf

7. Bulgaru, M., 1996, "The Right to Eat", Economic Publishing House, Bucharest.

8. George, G., Schillebeeckx, S., Liak, T., L., The management of natural resources: an overview and research agenda, Academy of Management

$52 \quad$ Review of International Comparative Management

Volume 19, Issue 1, March 2018 
Journal 2015, Vol. 58, No. 6, 1595-1613. http://dx.doi.org/10.5465 /amj.2015.4006

9. Knight, R., L., Bates, S., 2013, A New Century for Natural Resources Management, [E-book] Island Press/ https://islandpress.org/book.

10. Năstase M., Giuclea M., Bold O., 2012, "The Impact of Change Management in Organizations - a Survey of Methods and Techniques for a Successful Change", Review of International Comparative Management, Volume 13, Issue 1, pp. 5-16.

11. Sima, E., 2010, "The management of natural resources in the rural area", Agricultural Economics and Rural Development, New Series, Year VII, no. 1, pp. 67-86.

12. Stiglitz, J., 2005, Globalization. Hopes and disillusion, Economic Publishing House

13. Zimmermann, Erich. 1933. World Resources and Industries. New York: Harper \& Brothers.

14. Living Planet report 2008, WWF International, Downloads/living_planet_ report_2008.pdf

15. Community-based natural resource management, Published in 2006 by the WWF-World Wide Fund for Nature (formerly World Wildlife Fund) Southern African Regional Office (SARPO), http://assets.wwf.no/downloads /cbnrm_manual.pdf

16. Special Report on climate change, desertification, land degradation, sustainable land management, food security, and greenhouse gas fluxes in terrestrial ecosystems, Intergovernmental Panel on Climate Change, Working Group III (WGIII) - Mitigation of Climate Change, IPCC, Background report for the Scoping-Meeting https://www.ipcc.ch/report/sr2/pdf/sr2_background _report_final.pdf

17. National Rural Development Program, http://www.pndr.ro/

18. Romanian Statistical Yearbook, 2016 